\title{
Influence of Visceral Fat in the Outcomes of Colorectal Cancer
}

\author{
André Goulart ${ }^{a}$ b Nuno Malheiro ${ }^{b}$ Hugo Rios $^{a}$ Nuno Sousa ${ }^{b}$ Pedro Leão ${ }^{a}$ b \\ ${ }^{a}$ Department of General Surgery, Hospital de Braga, Braga, Portugal; ${ }^{b}$ Life and Health Sciences Research Institute \\ (ICVS), University of Minho, Braga, Portugal
}

\section{Keywords}

Visceral fat · Obesity $\cdot$ Colorectal cancer $\cdot$ Morbidity .

Survival

\begin{abstract}
Aim: To determine the relationship of visceral fat (VF) with the surgical outcome of the patients with colorectal cancer (CRC) submitted to curative surgery. Methods: Retrospective analysis of all patients submitted to CRC surgery during 3 years with a minimum of 5 years of follow-up. We assessed the length of hospital stay, complications, pathologic reports, surgical re-interventions and hospital re-admissions, relapses, survival time and disease-free time. VF was calculated based on patients' pre-operative CT-scan. The patients were divided into quartiles according to the VF area. Linear regression models and logistic regression models were used to establish a relationship between VF and all data collected. Results: The study included 199 patients (129 with colon cancer [CC] and 70 with rectal cancer). The average area of VF was $115.7 \mathrm{~cm}^{2}$. Patients with CRC revealed a direct relationship between VF and postoperative complications ( $p=$ $0.043)$, anastomotic leakage $(p=0.009)$ and re-operation ( $p=$ $0.005)$. The subgroup of patients with CC had an inverse as-
\end{abstract}

๑) 2018 S. Karger AG, Basel

\section{KARGER}

E-Mail karger@karger.com

www.karger.com/dsu sociation between VF and lymph nodes harvested ( $p=$ 0.027). Survival analyses did not reveal significant differences. Conclusion: VF has an influence on postoperative complications, anastomotic leakage and re-operation. A negative influence of $V F$ on lymph nodes harvested was observed on CC patients.

(c) 2018 S. Karger AG, Basel

\section{Introduction}

Colorectal cancer (CRC) is the third most common cancer in men (746,000 cases, $10.0 \%$ of the total) and the second in women $(614,000$ cases, $9.2 \%$ of the total) worldwide [1]. Obesity is a global health growing problem. According to the World Health Organization, 39\% of adults aged 18 years and over were overweight in 2014, and 13\% were obese [2]. In Portugal, like most developed countries, the prevalence of overweight is more than $50 \%[3,4]$.

Although body mass index has been used as one of the most reliable anthropometric indices of obesity because of its simplicity and objectivity, it does not reflect body adipose tissue accumulation, especially intra-abdominal or visceral fat (VF) tissue, and is not always consistent with VF area [5]. 
Waist circumference has been suggested to be a better marker for central obesity and is easier to obtain from patients. However, in some studies, it was proven to be insufficient to distinguish between subcutaneous and visceral fat [6]. A single slice area is sufficient to measure the abdominal fat [7]. Different levels are described in literature, but VF and subcutaneous fat quantification can be easily measured by single slice CT-scan going through the umbilicus [8].

Gastrointestinal surgeons know that the amount of fat can greatly influence the technical difficulty during abdominal surgery [9]. The increase of VF has been associated with a significant increase of surgical wound infection, anastomotic leak, re-interventions and an increase in post-operative hospital stay when compared to VF free patients [10-13]. However, other studies did not agree with this influence of VF [14]. The influence of VF on survival also remains unclear.

The main propose of this study is to evaluate the impact of VF on 30-days morbidity, tumor features and 5 -year survival on patients undergoing CRC surgery with curative intent.

\section{Material and Methods}

\section{Study Design and Selection of Patients}

A retrospective study that included all patients submitted to a curative CRC surgery at Hospital de Braga during 3 consecutive years (between January 2007 and December 2009) was conducted. Of the 355 patients reviewed, 45 patients were excluded because they were operated in an emergency setting and 27 patients were excluded because they had a metastatic disease at presentation (Dukes D). Of the remaining 283 patients, 84 were excluded because they had CT scans from outside hospitals and images were not available for analysis (Fig. 1).

\section{Data Collection}

Detailed information was obtained from the clinical records, which included demographic information, length of hospital stay, complications at 30-days (Clavien-Dindo Classification), re-operation or readmission at 30-days, anastomotic leakage and pathological reports. Anastomotic leakage was defined as an abscess or air near the anastomotic site that was diagnosed based on endoscopic and radiologic findings together with clinical symptoms and signs such as a change in drainage color or signs of peritonitis that required re-operation or antibiotic treatment (e.g., in patients with colorectal anastomotic leak submitted to anterior resection with protective ileostomy and no sign of sepsis).

Patient follow-up was conducted during 5 years or until death or the last contact date. Tumor recurrence, place of recurrence and date of recurrence were recorded.

A single cross-sectional scan at the level of the umbilicus was selected for fat quantification. A scientific image-analysis programme, ImageJ, was used for subcutaneous and VF area measure (http://imagej.nih.gov/ij). Subcutaneous fat was defined as fat that

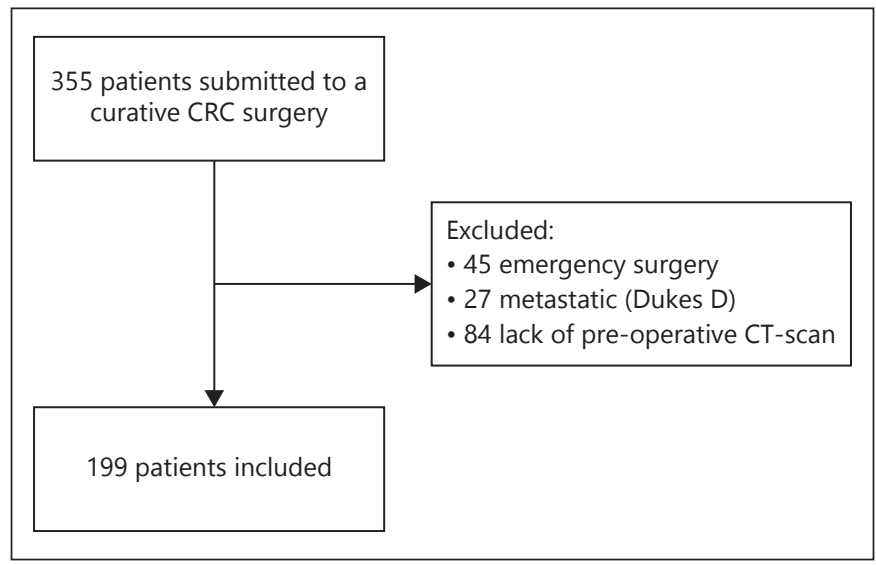

Fig. 1. Flowchart of the patients included in the study.

is superficial to the abdominal wall musculature, whereas VF is deep in the muscular wall and includes the mesenteric, subperitoneal and retroperitoneal parts (Fig. 2). For statistical analysis, VF area was divided into 4 quartiles.

\section{Data Analysis}

Descriptive statistics are presented as absolute (n) and relative (\%) frequencies for categorical variables, and mean (M) and $\mathrm{SD}$ for quantitative variables. The chi-square test was used to identify associations between dichotomous outcomes, and oneway analysis of variance was used to compare continuous variables. The Kaplan-Meier model with log-rank test was used to assess the impact of different characteristics on survival. A value of $p<0.05$ was considered significant. All statistical analysis was performed with the IBM SPSS Statistics 20 (SPSS Inc., Chicago, IL, USA).

\section{Ethical Issues and Informed Consent}

This retrospective study is based on recorded data study. Informed consent was not able to be obtained from every patient, but this study design and use of data for the purpose intended was approved by the Ethic Committee of Hospital de Braga. The authors made sure to safeguard the anonymity and confidentiality of all the participants.

\section{Results}

The study included 199 patients with CRC with an average age of 68 years, of whom 124 (62.3\%) were male. There were 129 patients with colon cancer (CC) and 70 with rectal cancer (RC). The clinicopathological characteristics of the patients are presented in Table 1.

Statistical analysis was performed for CRC patients group $(n=199)$ and for sub-groups of CC patients $(n=$ 129 ) and RC patients ( $n=70$; Table 2$)$.

The CCR group of patients presents significant differences in terms of 30 -days morbidity $(p=0.043)$, 

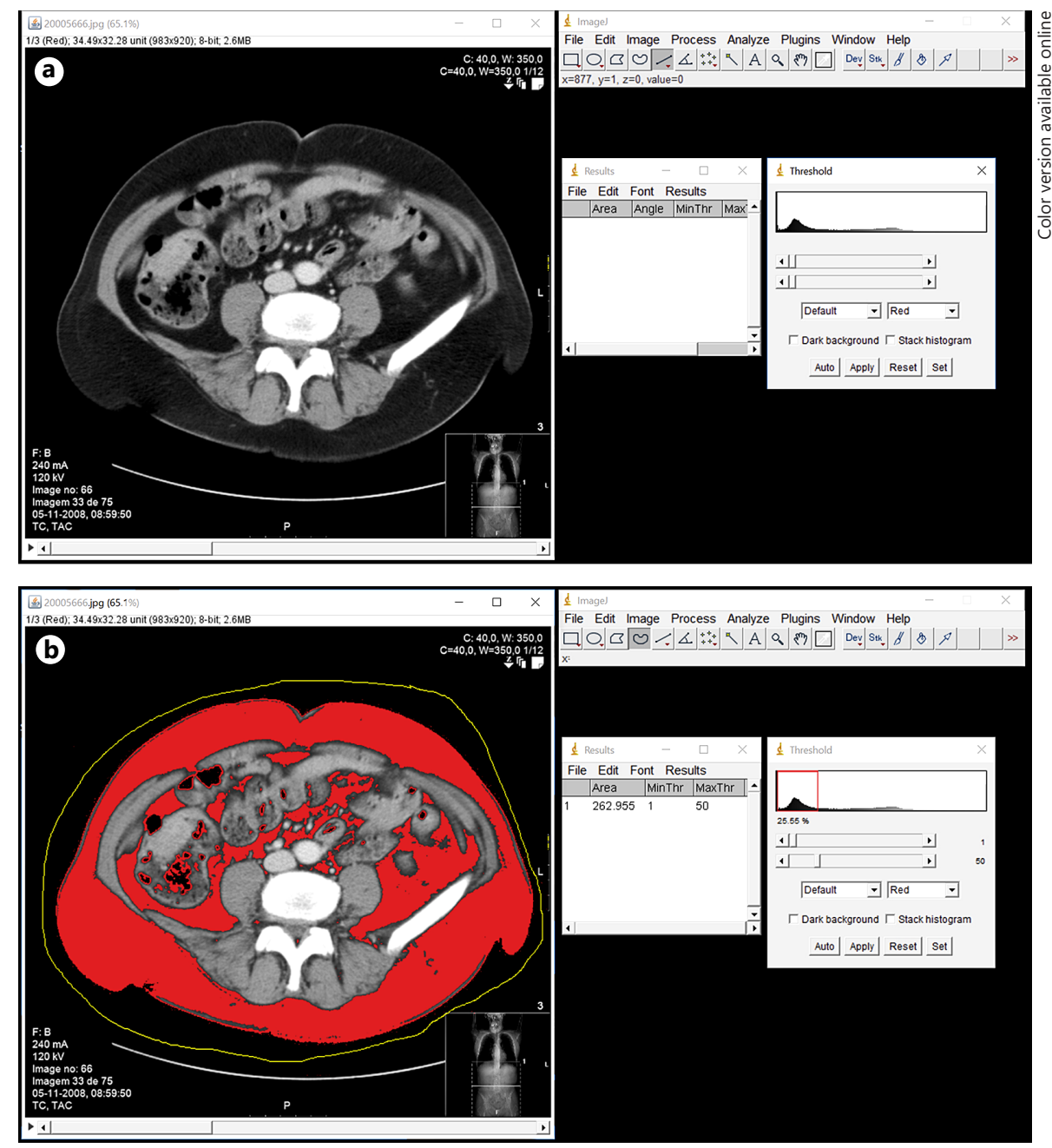

Fig. 2. Visceral fat (VF) quantification at Image J programme. a CT-scan. b Total fat measure $\left(262 \mathrm{~cm}^{2}\right)$. c VF measure $\left(61 \mathrm{~cm}^{2}\right)$.

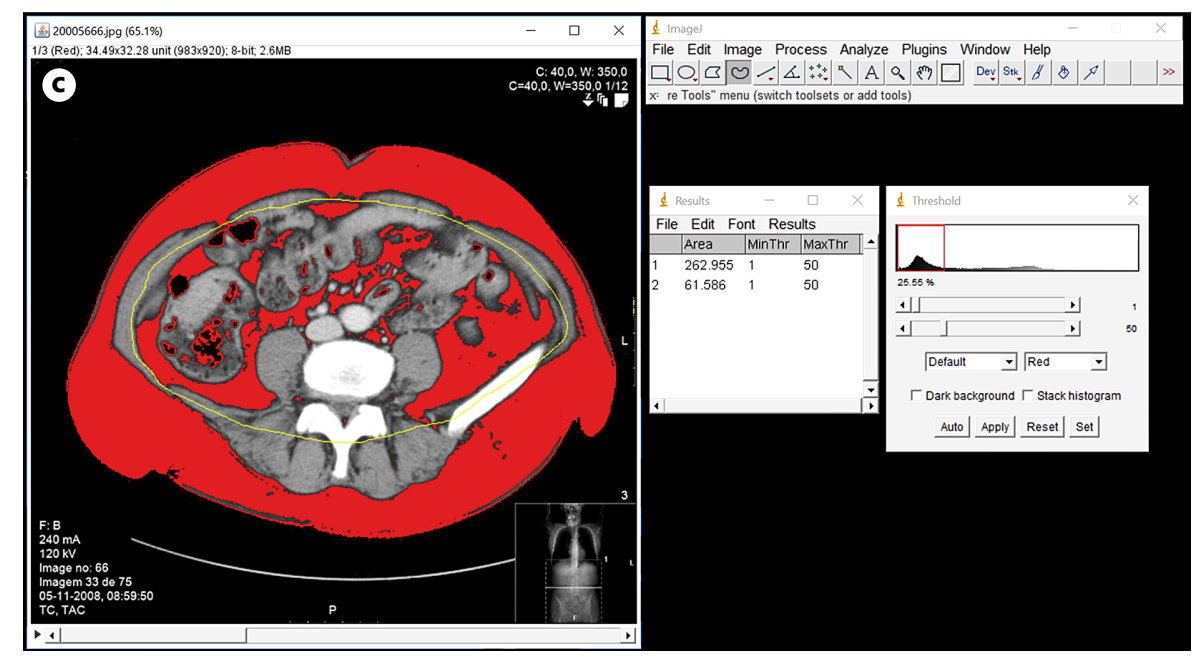


Table 1. Clinicopathological characteristics of patients

\begin{tabular}{|c|c|c|c|}
\hline Variables & CRC & $\mathrm{CC}$ & $\mathrm{RC}$ \\
\hline Number of patients & 199 & 129 & 70 \\
\hline Age, years & $68.2 \pm 11.0$ & $69.4 \pm 11.2$ & $68.4 \pm 10.8$ \\
\hline Gender, male, $\%$ & 62.3 & 66.7 & 54.3 \\
\hline \multicolumn{4}{|l|}{ ASA, $\%$} \\
\hline ASA I & 11.1 & 13.2 & 7.1 \\
\hline ASA II & 60.3 & 55.0 & 70.0 \\
\hline ASA III & 25.1 & 29.5 & 17.1 \\
\hline ASA IV & 1.0 & 0.8 & 1.4 \\
\hline Missing & 2.5 & 1.6 & 4.3 \\
\hline Laparoscopic surgery, \% & 3.5 & 4.7 & 1.4 \\
\hline \multicolumn{4}{|l|}{ Dukes classification, $\%$} \\
\hline Dukes A & 19.1 & 16.3 & 24.3 \\
\hline Dukes B & 40.7 & 45.7 & 31.4 \\
\hline Dukes C & 40.2 & 38.0 & 44.3 \\
\hline \multicolumn{4}{|l|}{ Lymph nodes } \\
\hline Positive, $n$ & $1 \pm 2.6$ & $1 \pm 2.5$ & $1 \pm 3.0$ \\
\hline Harvest, $n$ & $11 \pm 8.1$ & $11 \pm 7.8$ & $11 \pm 8.7$ \\
\hline$\geq 12$ lymph nodes harvested, \% & 37.7 & 39.7 & 33.8 \\
\hline Adjuvant QT, \% & 57.3 & 51.9 & 67.1 \\
\hline Post-operative hospital stay, days & $10.0 \pm 11.0$ & $9.8 \pm 10.8$ & $10.3 \pm 11.4$ \\
\hline 30-days morbidity, $\%$ & 25.1 & 24.0 & 27.1 \\
\hline Minor morbidity & 15.1 & 14.7 & 15.7 \\
\hline Major morbidity & 10.1 & 9.3 & 11.4 \\
\hline Anastomotic leak, \% & 7.5 & 7.0 & 8.6 \\
\hline Wound infection, \% & 17.6 & 16.3 & 20.0 \\
\hline 30-days re-operation, $\%$ & 7.0 & 7.0 & 7.1 \\
\hline 30-days re-admission, $\%$ & 4.0 & 3.9 & 4.3 \\
\hline 5 -years relapse, $\%$ & 26.8 & 24.0 & 31.9 \\
\hline 5-years mortality, \% & 38.2 & 37.2 & 40.0 \\
\hline Overall survival, years & $5.2 \pm 2.6$ & $5.2 \pm 2.6$ & $5.3 \pm 2.5$ \\
\hline Disease free survival, years & $4.6 \pm 3.0$ & $4.6 \pm 3.0$ & $4.6 \pm 2.9$ \\
\hline Total fat area, $\mathrm{cm}^{2}$ & $303.6 \pm 119.3$ & $291.7 \pm 114.8$ & $325.6 \pm 125.0$ \\
\hline Visceral fat area, $\mathrm{cm}^{2}$ & $115.7 \pm 63.3$ & $113.2 \pm 61.7$ & $120.2 \pm 66.4$ \\
\hline
\end{tabular}

CRC, colorectal cancer; CC, colon cancer; RC, rectal cancer; ASA, American Society of Anesthesiologists Score.

anastomotic leak $(p=0.009)$ and re-operation ( $p=$ 0.005). Despite not being statistically significant, the patients with more VF area present a long post-operative hospital stay, and more wound infections. Pathologic variables (Dukes stage and lymph nodes) were not statistically different between the quartiles of VF area.

The analyses of the CC sub-group revealed significant differences in terms of anastomotic leak $(p=0.008)$ and re-operation ( $p=0.008)$, like the in the CRC group. However, this sub-group also presented with significant differences on the number of lymph nodes harvested ( $p=$ 0.027 ) and the percentage of patients with at least 12 lymph nodes harvested $(p=0.003)$.
The RC sub-group presents no statistically different outcomes.

In terms of survival analysis, the Kaplan-Meier curves demonstrate that patients on the first and fourth quartiles have a slight better overall survival (Fig. 3) and diseasefree survival (Fig. 4), although this difference is not significant (log-rank $p=0.768$ and $p=0.704$, respectively).

\section{Discussion}

The influence of VF on outcomes in patients who were submitted to curative CRC surgery remains controversial. One of the reasons that explain part of this disagreement 
Table 2. Surgical and oncologic outcomes of CRC, CC, RC patients according to visceral fat area distribution into quartiles

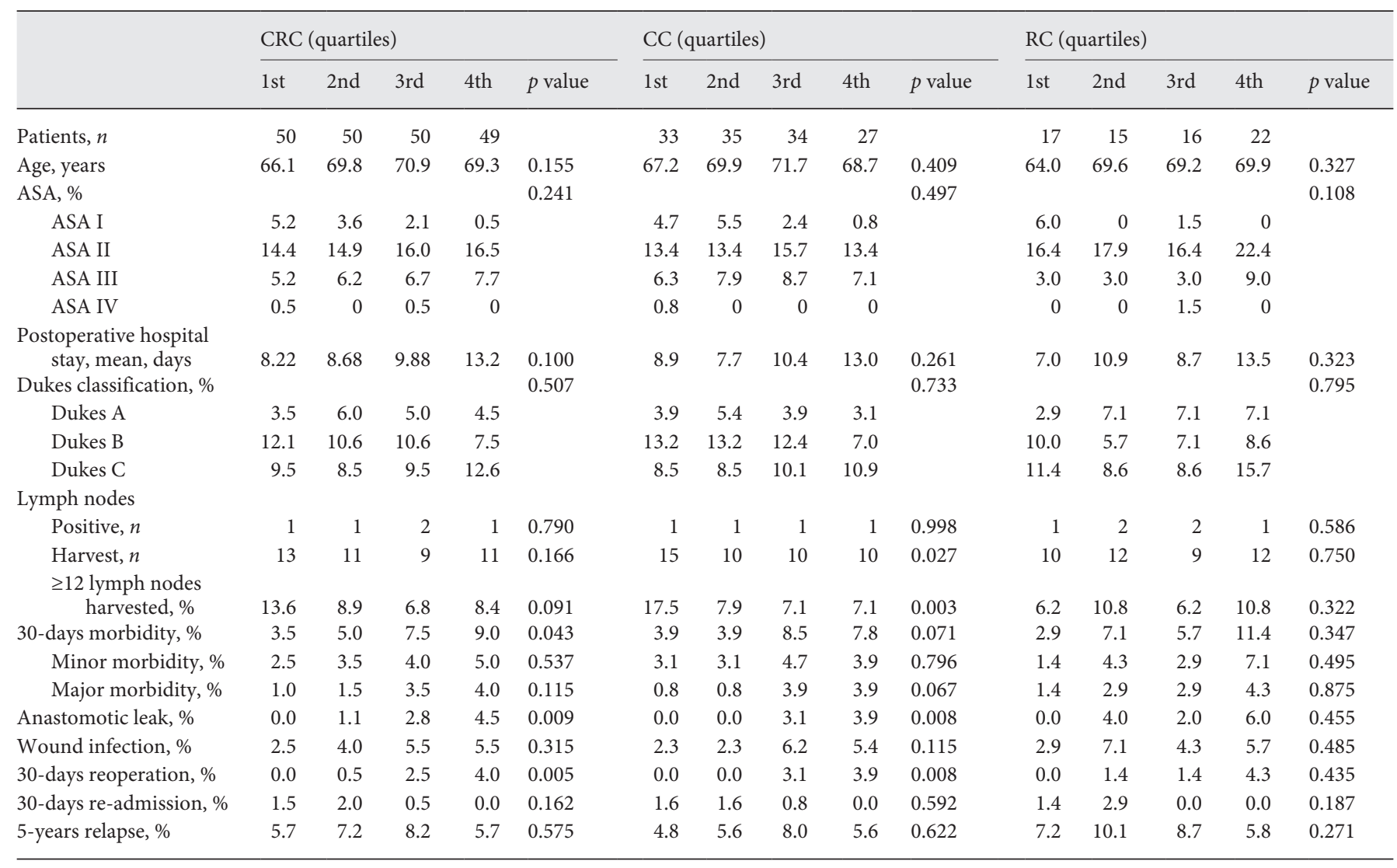

CRC, colorectal cancer; CC, colon cancer; RC, rectal cancer; ASA, American Society of Anesthesiologists Score.

may be the different definitions of VF used in the articles published: VF area or volume [11, 14-17], ratio between VF and subcutaneous fat area [10], ratio between VF and total fat area [12] and ratio between VF and body surface area [9]. In addition, the same definition, like for example VF area, has different cut-off points in different papers [18]. There is a necessity to determine the cut-off point of VF that defines obese patients in order to be able to compare results from different studies. In this paper, we used quartiles because we think that in our population the division of patients into quartiles may be more accurate.

Literature suggests that obese patients have a bigger risk of overall postoperative complications, surgical site infection, anastomotic leakage and colostomy complications [19-22]. A nationwide analysis from Sweden concluded that obese patients have increased post-operative complication rates [6]. A recent meta-analysis that aimed to determine the impact of visceral obesity on laparoscopic CRC surgery concluded that visceral obesity is associated with increased surgical difficulty and post-operative morbidity [18]. However, a recent paper suggested that VF has no influence on intraoperative difficulties, postoperative complications, and postoperative recovery in patients with sigmoid colon or RC [14].

In our study, VF had influence on 30-days morbidity, anastomotic leak and re-operation rates on CRC patients with statistically significant differences. Patients with more VF area appear to have more wound infections and longer hospital stay; however, our results were not statistically significant. These results corroborated most of the literature already published that propose that CRC patients with higher VF are prone to have more complications.

However, the most relevant oncologic result of our data is that CC patients with higher VF have significant differences on the number of lymph nodes harvested and the percentage of patients with at least 12 lymph nodes harvested (accurate tumor staging). Current guidelines, like NCCN, for CC treatment suggest that a minimum of 12 lymph nodes need to be examined to establish $\mathrm{N}$ stage [23]. Those guidelines recommend that less than 12 
Fig. 3. Overall survival analyzed by quartiles.

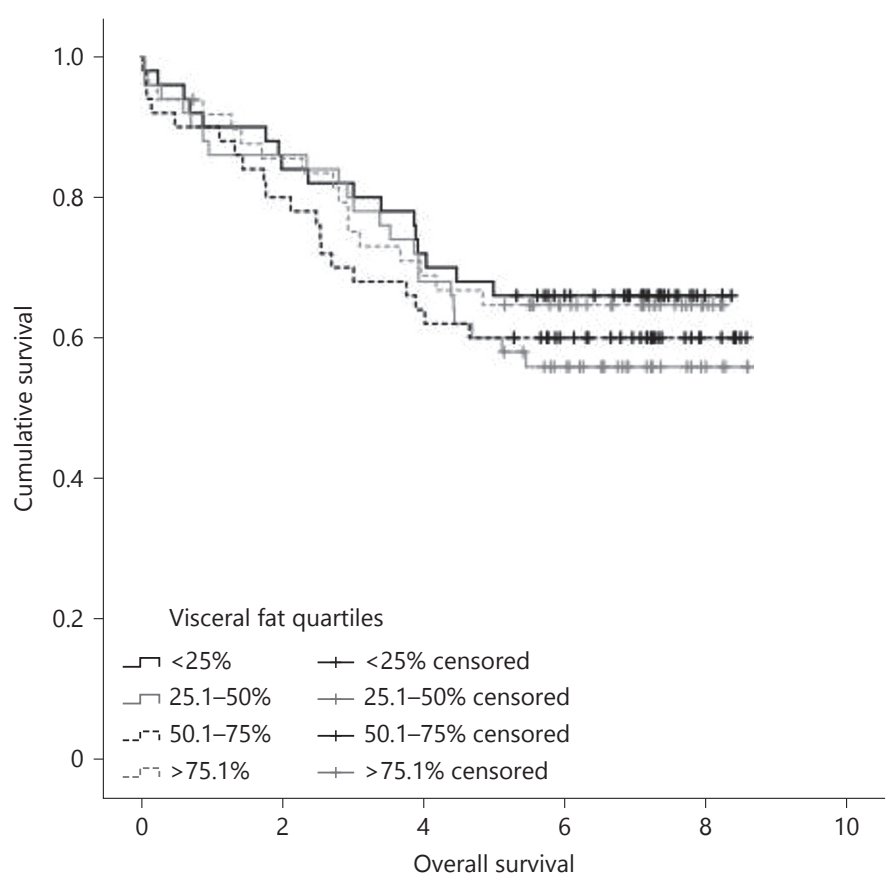

\begin{tabular}{|l|c|c|c|c|c|c|}
\hline Years & 0 & 2 & 4 & 6 & 8 & 10 \\
\hline $\begin{array}{l}\text { Number of } \\
\text { patients at risk }\end{array}$ & 199 & 166 & 135 & 99 & 19 & 0 \\
\hline
\end{tabular}

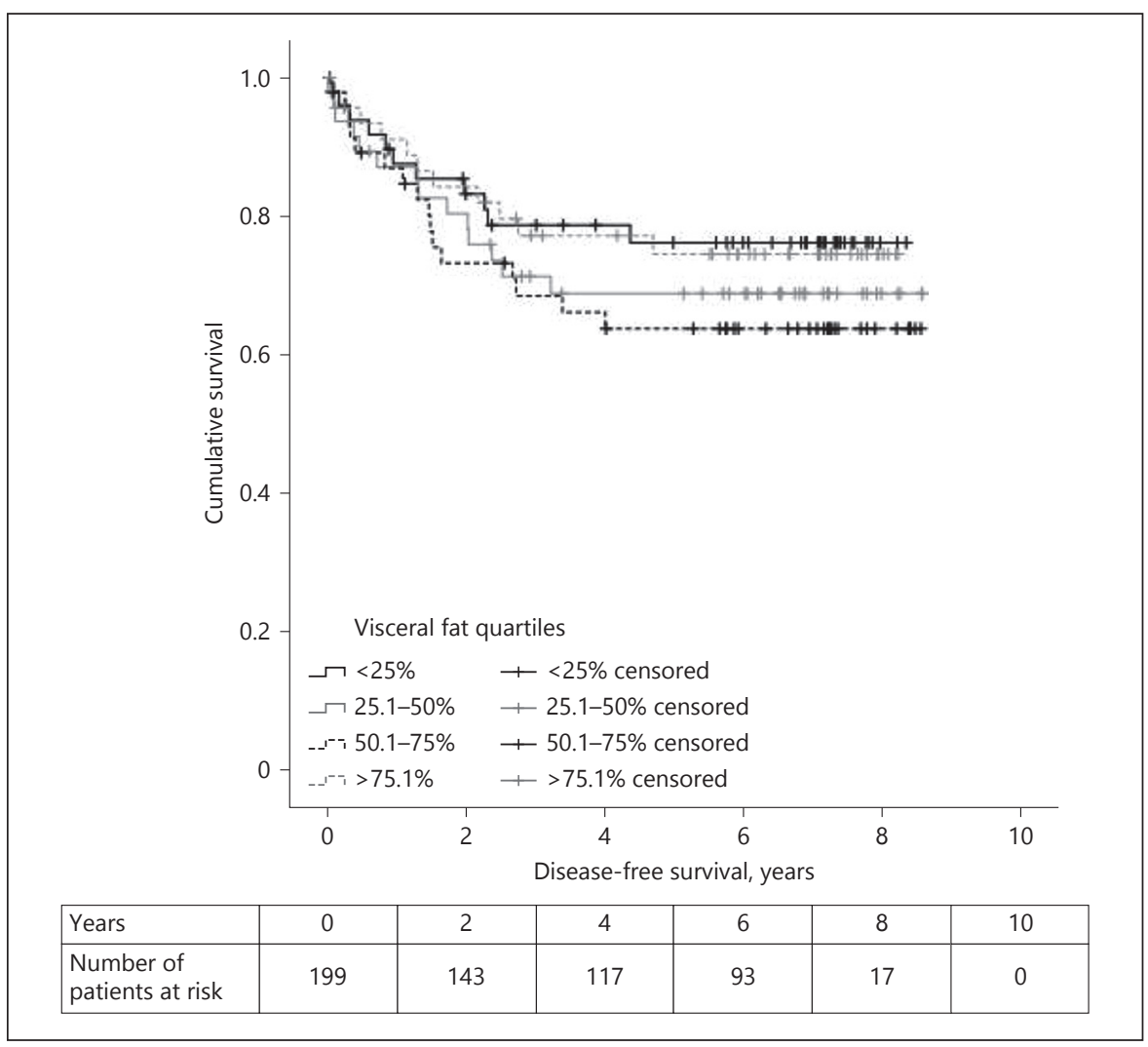

\begin{tabular}{|l|c|c|c|c|c|c|}
\hline Years & 0 & 2 & 4 & 6 & 8 & 10 \\
\hline $\begin{array}{l}\text { Number of } \\
\text { patients at risk }\end{array}$ & 199 & 143 & 117 & 93 & 17 & 0 \\
\hline
\end{tabular}


lymph nodes retrieved constitute the high-risk factors for recurrence and adjuvant chemotherapy is beneficial to those patients [23]. Some papers concluded that the number of nodes harvested from patients with higher VF was significantly smaller $[14,17,21]$ and others did not agree with this conclusion $[10,12]$. This difference of lymph nodes harvested that we found on CC patients can have 2 explanations: VF increases surgical difficulty presenting as a problem for the surgeon to perform an accurate oncologic dissection and fat tissue adhering to the mesentery and makes the identification of the lymph nodes difficult for the pathologist [18].

The RC sub-group analysis did not retrieve any statistical differences. One of the explanations can be the lower number of patients included (70 patients).

The influence of VF on survival remains controversial. One recent review of the literature that analyzes the influence of VF and cancer survival encountered 6 papers of CRC patients, and only 4 of these papers related VF to survival [24]. Another review concluded that the increase in adiposity was associated with an increase of CC-related mortality and decreased the disease-free survival of CC in women and RC in men [25]. Other papers suggested that increased VF was a significant predictor of worst diseasefree survival in patients with resectable CRC [10] and reduced overall survival in CRC patients receiving adjuvant chemotherapy [16]. In contrast, other works demonstrated that patients with higher VF tended to have better overall-survival that non-visceral obesity patients [12] and a meta-analyses concluded that there was insufficient evidence to prove the presence of a strong link between adiposity and survival [26]. Emerging literature reports the "obesity paradox" in cancer, which suggests that can- cer survival is U-shaped and that extremes of weight may have better survival $[27,28]$. Our results, although not statistically significant, show that patients on the first and fourth quartiles have a slight better overall survival and disease-free survival. We cannot explain why this happened, but maybe reflected some of the disagreement that exists around this.

The main limitations of this study include its retrospective design, which bears the issue of incomplete data and potential selection bias, and higher number of laparotomy, which does not reflect the current percentage of laparoscopy approach in CRC surgery.

\section{Conclusion}

The results suggest that VF increased likelihood of morbidity, anastomotic leakage and re-operations on CRC patients and lower number of lymph nodes harvest on the sub-group of CC patients.

The influence of VF in the number of lymph nodes harvested on CC patients are particularly interesting and should be verified in prospective trials with a larger set of patients. If the following studies support this difference in lymph nodes harvest, perhaps the most experienced surgeon and pathologist need to be called to deliver the best treatment to those patients.

\section{Disclosure Statement}

The authors certify that they have no conflicts of interest to disclose.

\section{References}

1 Ferlay J, Soerjomataram I, Ervik M, Dikshit R, Eser S, Mathers C, Rebelo M, Parkin D, Forman D, Bray F: GLOBOCAN 2012 v1.0, Cancer Incidence and Mortality Worldwide. International Agency for Research on Cancer, 2013. http://globocan.iarc.fr. 2016.

2 Word Health Organization. http://www.who. int/mediacentre/factsheets/fs311/en/ (accessed January 9, 2017).

3 do Carmo I, Dos Santos O, Camolas J, Vieira J, Carreira M, Medina L, Reis L, Myatt J, Galvao-Teles A: Overweight and obesity in Portugal: national prevalence in 2003-2005. Obes Rev 2008;9:11-19.

4 The State of Obesity. http://stateofobesity. org/files/stateofobesity2016.pdf (accessed January 9, 2017).
5 Bouchard C, Despres JP, Mauriege P: Genetic and nongenetic determinants of regional fat distribution. Endocr Rev 1993;14:72-93.

6 Hede P, Sorensson MA, Polleryd P, Persson $\mathrm{K}$, Hallgren T: Influence of BMI on shortterm surgical outcome after colorectal cancer surgery: a study based on the Swedish national quality registry. Int J Colorectal Dis 2015; 30:1201-1207.

7 Shen W, Punyanitya M, Wang Z, Gallagher D, St-Onge MP, Albu J, Heymsfield SB, Heshka $\mathrm{S}$ : Visceral adipose tissue: relations between single-slice areas and total volume. Am J Clin Nutr 2004;80:271-278.

8 Sottier D, Petit JM, Guiu S, Hamza S, Benhamiche H, Hillon P, Cercueil JP, Krause D, Guiu B: Quantification of the visceral and subcutaneous fat by computed tomography: interobserver correlation of a single slice technique. Diagn Interv Imaging 2013;94:879884

9 Seki Y, Ohue M, Sekimoto M, Takiguchi S, Takemasa I, Ikeda M, Yamamoto H, Monden M: Evaluation of the technical difficulty performing laparoscopic resection of a rectosigmoid carcinoma: visceral fat reflects technical difficulty more accurately than body mass index. Surg Endosc 2007;21:929934.

10 Moon HG, Ju YT, Jeong CY, Jung EJ, Lee YJ Hong SC, Ha WS, Park ST, Choi SK: Visceral obesity may affect oncologic outcome in patients with colorectal cancer. Ann Surg Oncol 2008;15:1918-1922. 
11 Tsujinaka S, Konishi F, Kawamura YJ, Saito M, Tajima N, Tanaka O, Lefor AT: Visceral obesity predicts surgical outcomes after laparoscopic colectomy for sigmoid colon cancer. Dis Colon Rectum 2008;51:1757-1765; discussion 1765-1767.

12 Park SW, Lee HL, Doo EY, Lee KN, Jun DW, Lee OY, Han DS, Yoon BC, Choi HS, Lee KH: Visceral obesity predicts fewer lymph node metastases and better overall survival in colon cancer. J Gastrointest Surg 2015;19:1513-1521.

13 Cakir H, Heus C, van der Ploeg TJ, Houdijk AP: Visceral obesity determined by CT scan and outcomes after colorectal surgery; a systematic review and meta-analysis. Int J Colorectal Dis 2015;30:875-882.

$14 \mathrm{Yu} \mathrm{H}$, Joh YG, Son GM, Kim HS, Jo HJ, Kim HY: Distribution and impact of the visceral fat area in patients with colorectal cancer. Ann Coloproctol 2016;32:20-26.

15 Park BK, Park JW, Ryoo SB, Jeong SY, Park KJ, Park JG: Effect of visceral obesity on surgical outcomes of patients undergoing laparoscopic colorectal surgery. World J Surg 2015; 39:2343-2353.

16 Lee CS, Murphy DJ, McMahon C, Nolan B, Cullen G, Mulcahy H, Sheahan K, Barnes E, Fennelly D, Ryan EJ, Doherty GA: Visceral adiposity is a risk factor for poor prognosis in colorectal cancer patients receiving adjuvant chemotherapy. J Gastrointest Cancer 2015; $46: 243-250$
17 Kang J, Baek SE, Kim T, Hur H, Min BS, Lim JS, Kim NK, Lee KY: Impact of fat obesity on laparoscopic total mesorectal excision: more reliable indicator than body mass index. Int J Colorectal Dis 2012;27:497-505.

18 Yang T, Wei M, He Y, Deng X, Wang Z: Impact of visceral obesity on outcomes of laparoscopic colorectal surgery: a meta-analysis. ANZ J Surg 2015;85:507-513.

19 De Raet J, Delvaux G, Haentjens P, Van Nieuwenhove Y: Waist circumference is an independent risk factor for the development of parastomal hernia after permanent colostomy. Dis Colon Rectum 2008;51:1806-1809.

20 Asteria CR, Gagliardi G, Pucciarelli S, Romano G, Infantino A, La Torre F, Tonelli F, Martin F, Pulica C, Ripetti V, Diana G, Amicucci G, Carlini M, Sommariva A, Vinciguerra G, Poddie DB, Amato A, Bassi R, Galleano R, Veronese E, Mancini S, Pescio G, Occelli GL, Bracchitta S, Castagnola M, Pontillo T, Cimmino G, Prati U, Vincenti R: Anastomotic leaks after anterior resection for mid and low rectal cancer: survey of the Italian society of colorectal surgery. Tech Coloproctol 2008;12: 103-110.

21 Watanabe J, Tatsumi K, Ota M, Suwa Y, Suzuki S, Watanabe A, Ishibe A, Watanabe $\mathrm{K}$, Akiyama H, Ichikawa Y, Morita S, Endo I: The impact of visceral obesity on surgical outcomes of laparoscopic surgery for colon cancer. Int J Colorectal Dis 2014;29:343-351.
22 Wick EC, Hirose K, Shore AD, Clark JM, Gearhart SL, Efron J, Makary MA: Surgical site infections and cost in obese patients undergoing colorectal surgery. Arch Surg 2011; 146:1068-1072.

23 National Comprehensive Cancer Network Colon Cancer (Version 1.2017). https://www. nccn.org/professionals/physician_gls/pdf/ colon.pdf (accessed January 9, 2017).

24 Xiao J, Mazurak VC, Olobatuyi TA, Caan BJ, Prado CM: Visceral adiposity and cancer survival: a review of imaging studies. Eur J Cancer Care (Engl) 2016, Epub ahead of print.

25 Siegel EM, Ulrich CM, Poole EM, Holmes RS, Jacobsen PB, Shibata D: The effects of obesity and obesity-related conditions on colorectal cancer prognosis. Cancer Control 2010;17: 52-57.

26 Parkin E, O'Reilly DA, Sherlock DJ, Manoharan P, Renehan AG: Excess adiposity and survival in patients with colorectal cancer: a systematic review. Obes Rev 2014;15:434451.

27 Caan BJ, Kroenke CH: Next Steps in Understanding the Obesity Paradox in Cancer. Cancer Epidemiol Biomarkers Prev 2017;26:12.

28 Kroenke $\mathrm{CH}$, Neugebauer R, Meyerhardt J, Prado CM, Weltzien E, Kwan ML, Xiao J, Caan BJ: Analysis of body mass index and mortality in patients with colorectal cancer using causal diagrams. JAMA Oncol 2016;2: $1137-1145$ 